\title{
IS MENTAL HEALTH LITERACY RELATED TO DIFFERENT TYPES OF COPING? COMPARING ADOLESCENTS, YOUNG-ADULTS AND ADULTS CORRELATES
}

\author{
Mariana Maia de Carvalho
Universidade de Coimbra, Faculdade de Psicologia e de Ciências da Educação da Universidade de Coimbra, \\ Coimbra, Portugal \\ marianaportoccarrero@hotmail.com \\ Maria da Luz Vale-Dias \\ Universidade de Coimbra, Faculdade de Psicologia e de Ciências da Educação da Universidade de Coimbra, \\ Coimbra, Portugal \\ valedias@fpce.uc.pt
}

\begin{abstract}
Introduction: Mental health literacy is associated with better mental health outcomes and believed to improve the way people cope with life challenges and manage mental health issues. Nevertheless, no study has yet empirically examined the relationships between mental health literacy and the use of coping strategies. Aims: This study aims to describe the levels of mental health literacy (literacy about mental illness and literacy about positive mental health) and the use of coping (coping styles) in adolescents, young-adults and adults; To explore the relationship between coping and mental health literacy in each age group; To compare if patterns of significant correlations vary across groups. Methods: This is a cross-sectional / exploratory design study. We have collected online and through paper-pencil method three developmental samples: adolescents aged between 15-18 years old ( $\mathrm{N}=240)$, young-adults aged between 19-36 (74) and adults aged between 37-75 ( $\mathrm{N}=105)$. Measures used were: Positive Mental Health Questionnaire PosMHLitq (Maia de Carvalho et al., in preparation) to evaluate literacy about positive mental health; the Mental Health Literacy Questionnaire MHLq (Campos et al., 2016; Dias et al., 2018) and the Portuguese adaptation of the Brief Cope by Pais Ribeiro and Tavares (2004) to control coping styles. Results: Across the three developmental groups, most coping styles are associated with both literacy about mental illness and literacy about mental well-being, but with different patterns of correlation between coping/literacy about mental well-being/coping/literacy about mental illness and between groups. The Use of Emotional Support is the only coping style significantly associated with both mental health literacy about mental illness and literacy about mental well-being in adolescents, young-adults and adults. Conclusions: Future research should examine this findings with longitudinal design.
\end{abstract}

Keywords: mental health literacy; coping; adolescents; young-adults; adults 


\section{IS MENTAL HEALTH LITERACY RELATED TO DIFFERENT TYPES OF COPING? COMPARING ADOLESCENTS, YOUNG-ADULTS AND ADULTS CORRELATES}

\section{RESUMEN}

¿Está la alfabetización en salud mental relacionada con diferentes tipos de afrontamiento? Comparando las correlaciones entre adolescentes, jóvenes-adultos y adultos. Introducción: La alfabetización en salud mental se asocia con mejores resultados en salud mental y se cree que mejora la forma en que las personas afrontan los retos de la vida y gestionan los problemas de salud mental. Sin embargo, ningún estudio ha examinado empíricamente las relaciones entre la alfabetización en salud mental y el uso de estrategias de afrontamiento. Objetivos: Este estudio pretende describir los niveles de alfabetización en salud mental (alfabetización sobre la enfermedad mental y alfabetización sobre la salud mental positiva) y el uso del afrontamiento (estilos de afrontamiento) en adolescentes, jóvenes-adultos y adultos; explorar la relación entre el afrontamiento y la alfabetización en salud mental en cada grupo de edad; comparar si los patrones de las correlaciones significativas varían entre los grupos. Métodos: Este es un estudio de diseño transversal/exploratorio. Hemos recogido online y mediante el método de lápiz-papel tres muestras evolutivas: adolescentes de entre 15-18 años ( $\mathrm{N}=240$ ), jóvenes-adultos de entre 19-36 años (74) y adultos de entre 37-75 años ( $\mathrm{N}=105)$. Las medidas utilizadas fueron: Cuestionario de Salud Mental Positiva PosMHLitq (Maia de Carvalho et al., en preparación) para evaluar la alfabetización sobre salud mental positiva; el Cuestionario de Alfabetización en Salud Mental MHLq (Campos et al., 2016; Dias et al., 2018) y la adaptación portuguesa del Brief Cope de Pais Ribeiro y Tavares (2004) para controlar los estilos de afrontamiento. Resultados: En los tres grupos de desarrollo, la mayoría de los estilos de afrontamiento se asocian tanto con la alfabetización sobre la enfermedad mental como con la alfabetización sobre el bienestar mental, pero con diferentes patrones de correlación entre afrontamiento/alfabetización sobre el bienestar mental/alfabetización sobre la enfermedad mental y entre los grupos. El uso de apoyo emocional es el único estilo de afrontamiento que se asocia significativamente tanto con la alfabetización sobre la enfermedad mental como con la alfabetización sobre el bienestar mental en adolescentes, jóvenes-adultos y adultos. Conclusiones: Las investigaciones futuras deberían examinar estos hallazgos con un diseño longitudinal.

Palabras claves: alfabetización en salud mental; afrontamiento; adolescentes; jóvenes-adultos; adultos

\section{INTRODUCTION}

Mental health literacy (MHL) has been framed as a multi-construct theory that entails both literacy about mental illness and positive mental health (Spike \& Hammer, 2019). The original definition of MHL integrated seven skills: recognizing and labelling adequately mental disorders; processing valid mental health information; exhibiting knowledge about risk factors; beliefs and information about the origins of mental illness; types of selfhelp available; types of professional help available and adequate help seeking actions (Jorm et al., 1997). This first approach was more oriented towards the identification, prevention and management of psychopathology, reflecting the pathogenic paradigm of mental health in which it has emerged (Wu et al., 2021). A later definition was influenced by World Health Organization (WHO, 2005) salutogenic conceptions of mental health and solid knowledge about dual nature of mental health and mental illness (lasiello et al., 2020) integrates Kutcher et al., (2016): knowledge about how to obtain and maintain good mental health. This was coined as positive mental health literacy (BjØrnsen et al., 2017) and emphasizes the importance of mental well-being for good mental health and prosperous development.

MHL is currently considered as an empowering tool for communities, as it enables people to prevent stigma (Lally et al., 2013), manage mental suffering and promote mental well-being, help-seeking (BjØrnsen et al., 2017, 2019; Bonabi et al., 2016; Chao et al., 2020; Lam, 2014; Rüsch et al., 2014) and help-giving (Rossetto et al., 2016), through the life-span. In this sense, MHL interventions lead to increased knowledge about mental disorders and mental well-being so as to less stigma and better help-seeking outcomes (BjØrnsen, 2019; Lo et al., 2017; Lubman et al., 2020; Xu et al., 2018).

Mental health is considered by WHO (2014) as a cumulative developmental process where risk and protective factors play competing roles. In this process, MHL can work as a protective factor that build cognitive and beha- 
vioural resources to cope with risk factors. For example, adolescence is characterized by multiple transformations that result in an increased sense of identity but can also be accompanied by the first onset of mental disorder (WHO, 2021). Hormonal transformations, a new body image, academic performance and vocational options may intensify levels of stress. Also, affective relationships with peers, in some cases, involve resisting peer pressure and avoiding bullying. In this context, MHL can establish the bounderies between healthy and unhealthy coping, normal mental health flows and pathology, or languishing (BjØrnsen et al., 2017; Lam, 2014).

In a later life stage, emerging-adulthood, developmental tasks continue to demand appropriate knowledge and coping in order to protect mental well-being. Generally, young-adults face elevated academic pressure, seek romantic relationships, try to find a job and conquer monetary autonomy in order to conduct their life project (Hutteman et al., 2014). This normative tasks reflect higher levels of responsibility that individuals have to cope with, while becoming adults. Considering this context, MHL interventions have been delivered in university settings to promote support and autonomy balance in mental health management (Lo et al., 2017).

Although in general this is a period of greater stability, normative adulthood also involves significant stressful moments for mental health, such as managing romantic relationship flows, dealing with losses, normative biological changes or diseases, taking care of family members and finances, while trying to find work-life balance (Hutteman et al., 2014). Considering that the prevalence of depression and anxiety disorders, at this age, is expressive (Westerhof \& Keyes, 2010), having knowledge to identify mental health risks and protect mental wellbeing may lead to using appropriate coping strategies (Zhou et al., 2010).

Based on the Transactional Model of Stress and Coping by Lazarus and Folkman (1984), it is considered that subjects are not passive while experiencing moments of stress but cope to minimize the effects of the situation. Indeed, developmental tasks can be framed as transactional moments of stress, in which individuals cope with contextual demands in order to maintain their well-being and minimize damages, losses or threats to their mental health (WHO, 2014). Numerous studies associate coping strategies to better mental health outcomes (Karademas, 2007; Park \& Adler, 2003; Zhou et al., 2010) and reinforce the role of coping in normative and non-normative development.

Although much is known about the prevalence of mental disorders and mental well-being across the life-span (Westerhof \& Keyes, 2010), the same can not be stated about the prevalence of mental health literacy, coping strategies and their correlates in different age stages. Additionaly, despite MHL s theoretical premise that better knowledge leads to better coping, no study has yet examined the relationship between $\mathrm{MHL}$ and coping or the mechanisms making interventions work. This study aimed to overcome this gap comparing adolescents, young-adults and adults mental health literacy and coping.

\section{AIMS}

This study aims to a) describe the levels of MHL (literacy about mental illness and literacy about positive mental health) and the use of coping (coping styles) in adolescents, young-adults and adults; b) to explore the relationship between coping and $\mathrm{MHL}$ in each age group; c) to know if patterns of significant correlations vary across groups.

\section{SAMPLE}

This study counted 419 participants from a community sample of the Portuguese population. Two samples were collected in order to assess different developmental groups: a sample of adolescents aged between 15-18 $(\mathrm{N}=240)$ and a sample of adults older than $18(\mathrm{~N}=179)$, but the sample of adults was split in young-adults $(\mathrm{N}=74)$ for subjects aged between 19-36 years old, and adults ( $N=105)$ for subjects older than 36 . The minimum age in this study is 15 and the maximum age is 75 .

In the adolescents' sample $54.6 \%$ are female and $45.4 \%$ are male, $24.1 \%$ are low socioeconomic status (SES), 57.5\% are medium SES, 18.3\% high SES, 68.3\% were collected online (during COVID-19 pandemic) and $31.7 \%$ pencil-paper (before pandemic). 


\title{
IS MENTAL HEALTH LITERACY RELATED TO DIFFERENT TYPES OF COPING? COMPARING ADOLESCENTS, YOUNG-ADULTS AND ADULTS CORRELATES
}

In the young-adult sample $75.7 \%$ are woman and $24.3 \%$ are men, $45.9 \%$ medium SES and $54.1 \%$ high SES. All subjects were assessed online, during pandemic.

In the adult sample $70.5 \%$ are woman and $29.5 \%$ are men, $1 \%$ low SES, $58.1 \%$ medium SES, $40 \%$ high SES. All subjects were assessed online, during pandemic.

\section{METHODS/INSTRUMENTS}

This is a cross-sectional / exploratory design study. Demographics: we assessed gender, SES, age. We used quantitative measures with reliable instruments validated for the Portuguese population.

\begin{abstract}
Adolescents:
Mental Health Literacy Questionnaire (MHLq, Campos et al., 2016): This is a self-report measure for mental health literacy, that in the multi-construct theory of mental health literacy reflects literacy about mental illness. The instrument is composed of 33 items ranked in 5-point Likert type options. The items are divided in three factors: First aid and help-seeking; Knowledge and stereotypes; Self-help strategies. A total rank can be extracted. In the original study internal consistency levels range from 0.72 to 0.79 . Although 7 additional questions measure the recognition of 7 disorders in vignette model, we did not used this part of the questionnaire.

Positive Mental Health Literacy Questionnaire (PosMHLq, Maia de Carvalho et al., in preparation): This questionnaire is self-rated and assessed literacy about mental well-being and positive mental health. It is used as a unidimensional measure of 20 items rated in a 5-point Likert type scale. In the original study internal consistency level was .93.

Brief Cope (Carver, 2007; Portuguese adaptation for adolescents by Maia de Carvalho et al., in preparation): This is a self-report measure of 28 items divided in 14 subscales: Humor, Using Emotional Support, Using Instrumental Support, Venting, Behavioral Disengagement, Acceptance, Positive Reframing, Active Coping, SelfBlame, Religion, Substance Use, Planning, Denial, Self-Distraction. Items are rated in four options from "I haven t been doing this at all" to "I have been doing this". The researcher can adapt items to measure situational or dispositional coping. In this study we evaluated dispositional coping. In the adaptation study for the Portuguese adolescent population internal consistency levels ranged from .50 to .79 .
\end{abstract}

\section{Young adults and Adults:}

Mental Health Literacy Questionnaire (MHLq, Dias et al., 2018): This instrument is the adaptation of MHLq (Campos et al., 2016) for adults. The instrument is composed of 29 items ranked in 5-point Likert type options. The items are divided in four factors: Knowledge mental health of problems; Erroneous beliefs and stereotypes; Help-seeking and first aid; self-help strategies. A total rank can also be extracted. In the original study internal consistency levels range from 0.72 to 0.84 .

Positive Mental Health Literacy Questionnaire (PosMHLq, Maia de Carvalho et al., in preparation): This questionnaire so as its version for adolescents, mentioned above, is self-rated. Answers are ranked in 5-point Likert type options. The adult's version has two subscales: Characteristics and Promoters of Positive Mental Health (17 items) and Vulnerability Factors of Positive Mental Health (3 items). The Characteristics and Promoters of Positive Mental Health subscale should be used to calculate the total sum of the measure. In the original study internal consistency levels of .92 are adequate.

Brief Cope (Carver, 2007; Portuguese adaptation for adults by Pais Ribeiro \& Tavares, 2004): In the adaptation study for the adult Portuguese population internal consistency levels were adequate from .55 to .84 .

\section{PROCEDURE}

This study is part of a larger research about mental health and well-being. It was approved by the Ethics Committee of the Faculty of Psychology and Educational Sciences of the University of Coimbra and the Ministry of Education and Sciences - General Direction of Education. 
Data collection had different moments. The adolescent sample was collected from March 2019 to June 2021, online (LimeSurvey) and paper-pencil. Secondary schools were contacted after the study was approved by the Ministry of Education and Sciences. First, we presented the study scope, its procedure and aims. After school directors authorized the study, legal tutors (parents) and participants gave their informed consent for data collection. Participants and legal tutors received information concerning the nature and ethics of the study specifically the anonymous and confidential character of the study, the right to withdraw the study, the voluntary nature of participation. The adults' sample was collected from March 2021 to July 2021 exclusively online, using a secure link from LimeSurvey platform. Information regarding the ethics of the study was also conceived before participants gave their informed consent. This sample was collected using snowball technique.

\section{RESULTS}

\section{Description of MHL, Coping in adolescents, young-adults and adults}

Levels of MHL (both positive mental health literacy and literacy about mental illness) are similar in the three developmental groups (cf. Table 1). Concerning coping styles, the major differences in the use of coping are in Religion, Substance Use, Behavioral Disengagement and Denial. Adults report increased levels of Religious coping compared to adolescents and young- adults. Adolescents refer significantly higher levels of Substance Use, Behavioral Disengagement and Denial. 
IS MENTAL HEALTH LITERACY RELATED TO DIFFERENT TYPES OF COPING? COMPARING ADOLESCENTS, YOUNG-ADULTS AND ADULTS CORRELATES
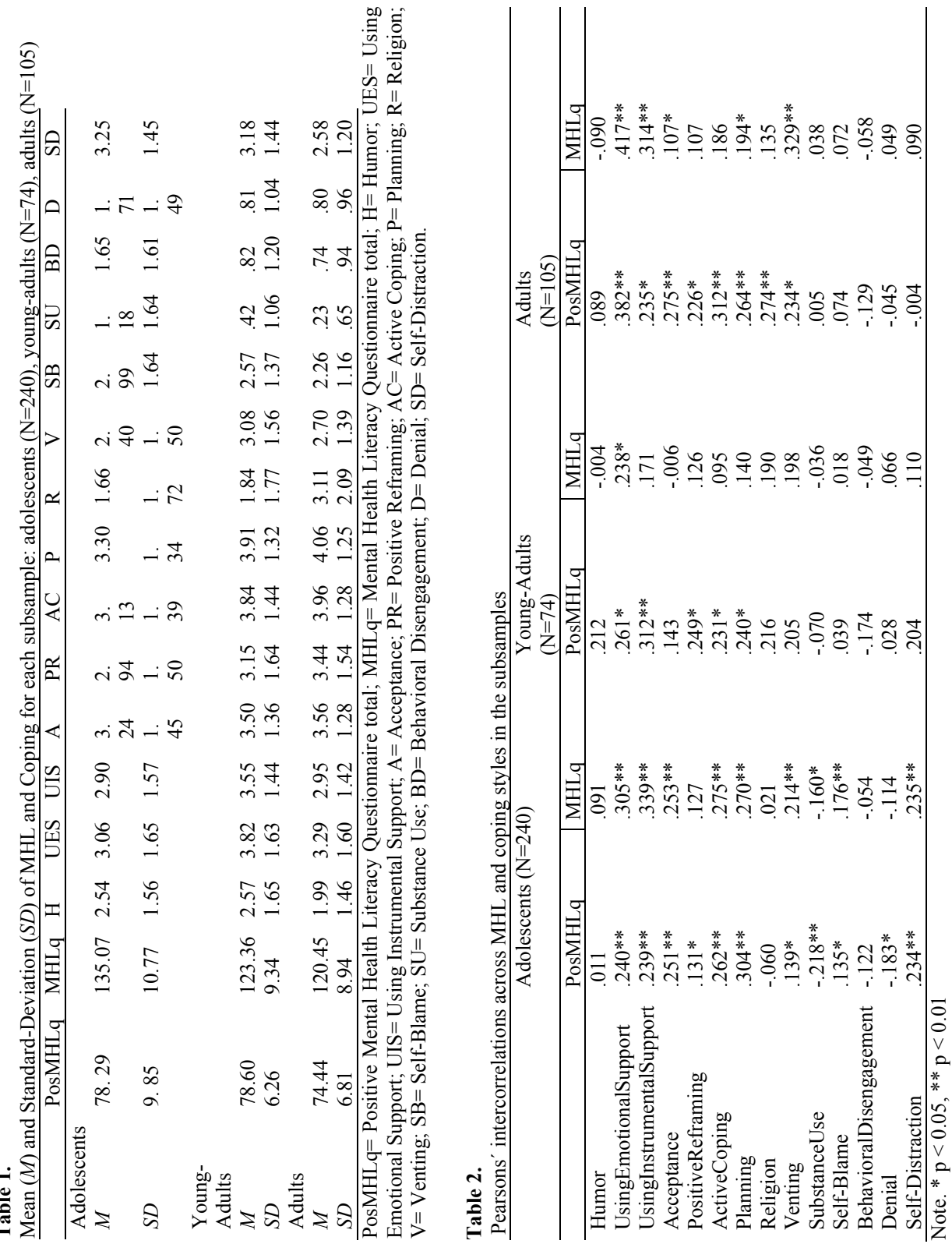
Mental health literacy and coping styles are related in all groups (cf. Table 2). Nevertheless, different patterns of correlates were found.

In adolescents, Humor, Behavioral Disengagement and Religion were not significantly related to PosMHLq or to MLHq. Positive Reframing $(r=.131 ; p<0.05)$ and Denial $(r=.-183 ; p<0.05)$ were significantly correlated with PosMHLq, but not with MHLq. Using Emotional Support ( $r=240 ; p<0.01)$, Using Instrumental Support $(r=$ $.239 ; p<0.01)$, Acceptance $(r=.262 ; p<0.01)$, Active Coping $(r=.262 ; p<0.01)$, Venting $(r=.139 ; p<0.05)$, Self-Blame $(r=.135 ; p<0.05)$, Substance Use $(r=-.218 ; p<0.01)$, and Self-Distraction $(r=.234 ; p<0.01)$ correlated significantly with PosMHLq and MHLq (Using Emotional Support $r=.305 ; p<0.01$; Using Instrumental Support $r=.339 ; p<0.01$; Acceptance $r=.253 ; p<0.01$; Active Coping $r=.275 ; p<0.01$; Venting $r=.214 ; p<$ 0.01; Self-Blame $r=.176 ; p<0.01$; Substance Use $r=-.160 ; p<0.05$; Self-Distraction $r=.235 ; p<0.01$ ).

In young-adults, only Using Emotional Support was correlated with both PosMHLq $(r=.261 ; p<0.05)$ and MHLq $(r=.238 ; p<0.01)$. Using Instrumental Support was correlated with PosMHLq $(r=.312 ; . p<0.01)$ but not with MHLq. Also Active Coping ( $r=.231 ; p<0.05)$, Positive Reframing $(r=.249 ; p<0.05)$ and Planning $(r=.240$; $p<0.05)$ were positively and significantly correlated with PosMHLq but not with MHLq.

In the adults sample Using Emotional Support $(r=.382 ; p<0.01)$, Using Instrumental Support $(r=.235 ; p<$ $0.05)$, Acceptance $(r=.275 ; p<0.01)$, Positive Reframing $(r=.226 ; p<0.05)$, Planning $(r=; p<0.05)$ and Venting $(r=.234 ; p<0.05)$ were correlated with PosMHLq and MHLq (Using Emotional Support $r=.417 ; p<0.01$; Using Instrumental Support $r=.314 ; p<0.01$; Acceptance $r=.107 ; p<0.05$; Planning $r=.194 ; p<0.05$; Venting $r=.329$; $p<0.05)$.

Active Coping $(r=.312 ; p<0.01)$ and Religion $(r=.274 ; p<0.01)$ were only correlated with PosMHLq.

Across the three developmental subsamples, the only coping style correlated with both PosMHLq and MHLq is Using Emotional Support.

Using Instrumental Support, Positive Reframing, Active Coping and Planning are correlated with PosMHLq in all subsamples.

Using Instrumental Support is correlated with MHLq in adolescents and adults but not in young-adults. Acceptance, Venting and Planning are related with PosMHLq and MHLq in adolescents and adults but not in the younger adults group.

\section{DISCUSSION}

This study was a first attempt to observe the interaction between mental health literacy and coping, so as their correlates across different developmental stages.

In terms of use of coping, religious coping was higher among the adults sample, reflecting cultural changes in religious adherence in adolescents and young-adults. Substance Use, Behavioral Disengagement and Denial were used less frequently by adolescents than other adaptative strategies. Nevertheless, adolescents use of these styles, considered elsewhere as avoidance coping styles is higher than the pattern referred by young-adults and adults, suggesting that adolescents show higher risk of substance abuse and behavioral problems (WHO, 2021). Nonetheless, two notes should be made. First, low SES was more prevalent in the adolescent sample than in the young-adult and adult sample, which can influence the type of coping used, as well. On the other hand, as we used self-report measures, we should also consider that young-adults and adults may be more ashamed to report using avoidance coping strategies than adolescents. Future studies should examine these findings using external measures.

Concerning the correlates of coping and MHL, Using Emotional Support was the only coping style related to positive mental health literacy and literacy about psychopathology in all developmental groups. Previous research has shown MHL was associated negatively with loneliness (BjØrnsen et al., 2019) and influences help-seeking behavior (Chao et al., 2020; Lubman et al., 2020; Xu et al., 2018). Our finding indicates that Using Emotional Support may be influenced by both the drive to promote mental well-being and to prevent mental illness. 


\section{IS MENTAL HEALTH LITERACY RELATED TO DIFFERENT TYPES OF COPING? COMPARING ADOLESCENTS, YOUNG-ADULTS AND ADULTS CORRELATES}

As expected, positive mental health literacy is related to more adaptative forms of coping like Using Instrumental Support, Positive Reframing, Planning and Active Coping in all subsamples. People who know more about mental well-being may feel more capable and competent to face life challenges and protect their well-being. Qualitative research has suggested previously the relationship between MHL and adaptative coping (Wholoshyn \& Savage, 2021) but this was the first empirical study to explore it.

Interestingly, adolescents and adults who know more about mental illness use more instrumental support, Active Coping, Planning, Venting but not young-adults. We suspect that this finding must be explained by the reduced size off the young-adults sample, in this sense, these results should be replicated with bigger and more balanced samples.

Adolescents with higher levels of MHL report less use of Denial and Substance Use or Behavioral Disengagement. MHL appears to have a protective effect concerning risk behavior and emotion regulation strategies (Lubman et al., 2020) in this developmental period but not in subsequent ages. Futures studies should examine if there is a "loss" effect using longitudinal designs.

Unexpectedly, Self-Blame was positively associated to MHL. Once MHL should have an anti-stigma effect and clarify how self-criticism is a detrimental strategy for mental health, this result was not consistent with MHL theory. Nevertheless, with awareness about mental health issues and mental well-being may come more responsibility and the drive to behave more adaptatively, explaining the relation with Self-Blame. Qualitative studies should explore these findings.

Finally, it is important to note that PosMHLq, more than MHLq, was associated to most coping styles. Literacy about positive mental health and well-being may help, at least, community samples to cope better with normative events than literacy about mental illness.

It would be worthy to replicate this study with clinical samples, and controlling life events.

This study adds important findings to $\mathrm{MHL}$ and coping research, so as to developmental theory. Nevertheless, caution should be taken while interpreting the results. We used self-report measures, the size of the samples is not the same and our design is cross-sectional. Future studies should overcome these limitations by using different measures, as interviews, bigger and more balanced samples and longitudinal design.

The predictive effect of MHL on the use of coping and mental health should be further explored.

\section{CONCLUSION}

Mental health literacy is related to the use of coping styles. Interventions promoting MHL should invest in positive mental health literacy and literacy about mental illness in order to increase adaptative coping. Futures studies should control the effect of MHL initiatives on coping and mental health.

\section{BIBLIOGRAPHIC REFERENCES}

BjØrnsen, H. N., Eilertsen, M. E. B., Ringdal, R., Espnes, G. A., \& Moksnes, U. K. (2017). Positive mental health literacy: development and validation of a measure among Norweguian adolescentes. BMC Public Health, 17, 717. https://doi.org/10.1186/s12889-017-4733-6

BjØrnsen, H. N., Espnes,G.A., Eilertsen, M.E.B., Ringdal,R., \& Moksnes, U.K. (2019). The relationship between positive mental health literacy and mental well-being among adolescents: implications for school health services. The Journal of School Nursing, 20(10), 1-10. https://doi.org/10.1177/1059840517732125

Bonabi, H., Müller, M., Ajdacic-Gross, V., Eisele, J., Rodgers, S., Seifritz, E., Rössler, W., \& Rüsch, N. (2016). Mental health literacy, attitudes to help-seeking, and perceived need as predictors of mental health service use: a longitudinal study. The Journal of Nervous and Mental Disease, 204 (4), 321-324. https://doi.org/ $10.1097 / \mathrm{nmd} .0000000000000488$

Campos, L., Dias, P., Palha, F., Duarte, A., \& Veiga, E. (2016). Development and psychometric properties of a new questionnaire for assessing Mental Health Literacy in young people. Universitas Psychologica, 15(2), 61-72. 
https://doi.org/10.11144/Javeriana.upsy15-2.dppq

Chao, H.-J., Lien, Y.-J., Kao, Y.-C., Tasi, I.-C., Lin, H.-S., \& Lien, Y.-Y. (2020). Mental Health Literacy in Healthcare Students: An Expansion of the Mental Health Literacy Scale. Int. J. Environ. Res. Public Health, 17, 948. https://doi.org/10.3390/ijerph17030948

Carver, C. S. (1997). You want to measure coping but your protocol's too

long: Consider the Brief COPE. International Journal of Behavioral Medicine, 4, 92-100. https://doi.org/10.1207/s15327558ijbm0401_6

Hutteman, R., Hennecke, M., Orth, U., Reitz, A. K., \& Specht, J. (2014). Developmental

Tasks as a Framework to Study Personality Development in Adulthood and Old Age. European Journal of Personality, 28(3), 267-278. https://doi.org/10.1002/per.1959

Iasiello, M., van Agteren, J., \& Muir-Cochrane, E. (2020). Mental Health and/or Mental IIIness: a Scoping Review of the Evidence and Implications of the Dual_Continua Model of Mental Health. Evidence Base, (1). https://doi.org/10.21307/ed-2020-001

Jorm, A. F., Korten, A. E., Jacomb, P. A., Christensen, H., Rodgers, B., \& Pollit, P. (1997). "Mental health literacy": a survey of the public's ability to recognise mental disorders and their beliefs about the effectiveness of treatment. Medical Journal of Australia, 166, 182-186. https://doi.org/10.5694/j.1326-5377.1997.tb140071.x

Karademas, E. C. (2007). Positive and Negative Aspects of Well-being: Common and

$\begin{array}{lll}\text { Specific Predictors. Personality and Individual } \quad \text { Differences, } & 43,\end{array}$ https://doi.org/10.1016/j.paid.2006.11.031

Kutcher S., Wei Y., \& Coniglio, C. (2016). Mental health literacy; past, present and future. Canadian Journal of Psychiatry, 61(3), 154-158. https://doi.org/10.1177/0706743715616609.

Lally, J., ó Conghaile, A., Quigley, S., Bainbridge, E., \& McDonald, C. (2013). Stigma of mental illness and helpseeking intention in university students. The Psychiatrist, 37(8), 253260. https://doi.org/10.1192/pb.bp.112.041483

Lam, L. T. (2014). Mental health literacy and mental health status in adolescents: A population-based survey. Child and Adolescent Psychiatry and Mental Health, 8, 26.

https://doi.org/10.1186/1753-2000-8-26

Lazarus, R. S., \& Folkman, S. (1984). Stress, Appraisal, and Coping. New York: Springer.

Lo, K., Gupta, T., \& Keating, J. (2018). Interventions to Promote Mental Health Literacy

in Universiy Students and Their Clinical Educators. A systematic review of randomized control trials. Health Professions Education, 4(3), 161-75. https://doi.org/10.1016/j.hpe.2017.08.001

Lubman, D. I., Cheetham, A., Sandral, E., Wolfe, R., Martin, C., Blee, F., Berridge, B. J.,

Jorm, A. F., Wilson, C., Allen, N. B., McKay-Brown, L., \& Proimos, J. (2020). Twelve-month outcomes of MAKINGtheLINK: A cluster randomized controlled trial of a school-based program to facilitate help-seeking for substance use and mental health problems. EClinicalMedicine, 18, 100225. https://doi.org/10.1016/j.eclinm.2019.11.018

Müller, M., Ajdacic-Gross, V., Eisele, J., Rodgers, S., Seifritz, E., Rössler, W., \& Rüsch, N. (2016). Mental health literacy, attitudes to help-seeking, and perceived need as predictors of mental health service use: a longitudinal study. The Journal of Nervous and Mental Disease, 204 (4), 321-324.

https://doi.org/10.1097/nmd.0000000000000488

Park, C. L., \& Adler, N. E. (2003). Coping style as a predictor of health and well-being across the first year of medical school. Health Psychology, 22, 627-631. https://doi.org/10.1037/0278-6133.22.6.627

Pais-Ribeiro, J. L., \& Rodrigues, A. P. (2004). Questões acerca do coping: a propósito do estudo de adaptação do Brief Cope. Psicologia, Saúde \& Doenças, 5 (1), 3-15.

Rossetto, A., Jorm, A. F., \& Reavley, N. J. (2016). Predictors of adults' helping intentions and behaviours towards a person with a mental illness: A six-month follow-up study. Psychiatry research, 240, 170-176. 


\section{IS MENTAL HEALTH LITERACY RELATED TO DIFFERENT TYPES OF COPING? COMPARING ADOLESCENTS, YOUNG-ADULTS AND ADULTS CORRELATES}

https://doi.org/10.1016/j.psychres.2016.04.037

Spiker, D. A., \& Hammer, J. H. (2019). Mental health literacy as theory: current challenges and future directions. Journal of mental health (Abingdon, England), 28(3), 238-242. https://doi.org/10.1080/09638237.2018.1437613

Westerhof, G. L., \& Keyes, C. L. M. (2010). Mental illness and mental health: the two continua model across the lifespan. Journal of Adult Development, 17, 110 - 119. https://doi.org/10.1007/s10804-009-9082-y

Woloshyn, V., \& Savage, M. (2018): Increasing teacher candidates' mental health literacy and stress coping skills through an elective mental health and wellness course. International Journal of Inclusive Education. https://doi.org/10.1080/13603116.2018.1497097

World Health Organization. (2005). Promoting mental health: Concepts, emerging evidence, practice. WHO.

World Health Organization \& Calouste Gulbenkian Foundation (2014). Social determinants of mental health. WHO.

World Health Organization. (2021). Guidelines on mental health promotive and preventive interventions for adolescents: helping adolescents thrive. Executive summary. WHO.

Xu, Z., Huang, F., Kösters, M., Staiger, T., Becker, T., Thornicroft, G., \& Rüsch, N.

(2018). Effectiveness of interventions to promote help-seeking for mental health problems: Systematic review and meta-analysis. Psychological Medicine, 48(16), 2658-2667. https://doi.org/10.1017/S0033291718001265

Wu, J., Zhang, L., Zhu, X., \& Jiang, G. (2021). Mental Health Literacy from the

Perspective of Multi-Field Experts in the Context of Chinese Culture. International Journal of Environmental Research Public Health, 18, 1387. https://doi.org/10.3390/ijerph18041387

Zhou, E. S., Penedo, F. J., Bustillo, N. E., Benedict, C., Rasheed, M., Lechner, S.,

Soloway, M., Kava, B. R., Schneiderman, N., \& Antoni, M. H. (2010). Longitudinal Effects of Social Suport and Adaptative Coping on Emotional Well-Being of Survivers of Localized Prostate Cancer, The Journal of Supportive Oncology, 8, 196-201. 